Volume 2 Nomor 1, Januari-Juni 2018: hlm. 67-74. Magister Ilmu Hukum, Fakultas Hukum, Universitas Lampung, Bandar Lampung, Lampung, Indonesia.

E-ISSN: 2598-3105 P-ISSN: 2723-2581 http://jurnal.fh.unila.ac.id/index.php/cepalo

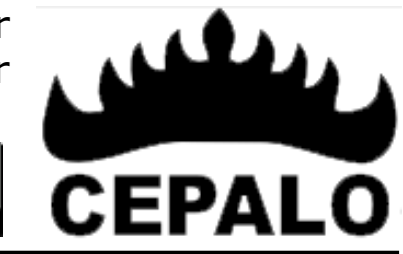

\title{
PENGATURAN DAN IMPLEMENTASI HOSPITAL BYLAWS DI PROVINSI LAMPUNG (STUDI PADA RUMAH SAKIT DI KABUPATEN LAMPUNG TENGAH)
}

\section{HOSPITAL BY LAWS ARRANGEMENT AND IMPLEMENTATION IN LAMPUNG PROVINCE (STUDY AT HOSPITALS IN CENTRAL LAMPUNG DISTRICT)}

\author{
Yulfrina Andriani \\ Rumah Sakit Umum Daerah Lampung Tengah \\ riyandrie@yahoo.com
}

\begin{abstract}
Abstrak
Pada dasarnya rumah sakit adalah organisasi yang kompleks karena mengatur seluruh kegiatan dan kebijakan yang didalamnya terdapat berbagai macam profesi dengan tugas dan responsibilitas yang berbeda namun memiliki hubungan dalam memberikan pelayanan terhadap masyarakat di bidang kesehatan. Sebuah rumah sakit memerlukan suatu pedoman sebagai acuan dalam penyelenggaraan rumah sakit dan juga memiliki tujuan untuk melindungi semua pihak yang terlibat dalam pelayanan di rumah sakit. Peraturan tersebut adalah hospital bylaws. Penelitian ini dilakukan untuk mengetahui bagaimana peran hospital bylaws didalam sebuah rumah sakit, apa saja aspek hukum keperdataan yang harus ada didalam sebuah hospital bylaws dan apakah keberadaan hospital bylaws ini sudah memberikan perlindungan hukum terhadap pemilik, pemimpin utama rumah sakit dan pegawai medis. Penelitian ini dilakukan dengan melalui pendekatan yuridis normatif serta ditunjang dengan pendekatan yuridis empiris. Data-data didapat melalui studi pustaka dan studi lapangan. Analisis data dilakukan secara kualitatif. Hasil penelitan menunjukkan bahwa eksistensi hospital bylaws rumah sakit di Kabupaten Lampung Tengah masih belum sepenuhnya sesuai dengan Peraturan Menteri Kesehatan RI Nomor 772 Tahun 2002, tidak semua aspek hukum keperdataan termuat di dalam hospital bylaws, rumah sakit masih mengganggap bahwa hospital bylaws belum mampu memberikan perlindungan hukum terhadap pemimpin utama rumah sakit, pegawai medis bahkan pemilik.
\end{abstract}

Kata Kunci: Eksistensi, Hospital Bylaws, Perlindungan Hukum

\begin{abstract}
Abstrak
Basically, a hospital is a complex organization because it regulates all activities and policies in which there are various professions with different duties and responsibilities but have a relationship in providing services to the public in the health sector. A hospital requires a guideline as a reference in the organization of a hospital and also has the aim to protect all parties involved in hospital services. The regulation is hospital bylaws. This study was conducted to find out how the role of hospital bylaws in a hospital, what aspects of civil law must exist in a hospital bylaws and whether the presence of this hospital bylaws has provided legal protection to owners, key leaders of the hospital and medical staff. This research was conducted through a normative juridical approach and supported by an empirical juridical approach. Data obtained through literature study and field studies. Data analysis was carried out qualitatively. Research results show that the existence of hospital bylaws in Central Lampung regency is still not fully in accordance with the Regulation of the Minister of Health RI Number 772 of 2002, not all aspects of civil law are contained in hospital bylaws, hospitals still assume that hospital bylaws have not been able to provide legal protection against the main leaders of hospitals, medical employees and even owners.
\end{abstract}

Keywords: Existence, Hospital By laws, Legal Protection 
Cara Mengutip (How to Cite): Yulfrina Andriani, "Pengaturan dan Implementasi Hospital by Laws di Provinsi Lampung (Studi pada Rumah Sakit di Kabupaten Lampung Tengah)”, Jurnal Cepalo, 2 (1), (2018): 67-74.

DOI: https://doi.org/10.25041/cepalo.v2no1.1763

\section{A. Pendahuluan}

Berdasarkan ketentuan Pasal 1 angka 1 Undang-Undang Nomor 44 Tahun 2009 Tentang Rumah Sakit (selanjutnya disebut UU RS), Rumah sakit adalah institusi pelayanan kesehatan yang menyelenggarakan pelayanan kesehatan perorangan secara paripurna yang menyediakan pelayanan rawat inap, rawat jalan dan gawat darurat. Setiap rumah sakit mempunyai kewajiban untuk menyusun dan melaksanakan peraturan internal rumah sakit (hospital bylaws), sebagaimana ditentukan dalam pasal 29 ayat (1) huruf r UU RS. Peraturan internal rumah sakit (hospital by laws) adalah peraturan yang disusun untuk mengatur tata cara dalam membentuk perusahaan dan klinis yang baik (good clinical governance) meliputi peraturan organisasi rumah sakit (corporate bylaws) dan peraturan pegawai medis rumah sakit (medical staff bylaws).

Rumah sakit adalah salah satu organisasi yang cukup khas dan berbeda dibandingkan dengan lembaga lainnya. Organisasi rumah sakit sangatlah kompleks, karena mengatur seluruh kegiatan dan kebijakannya yang terdiri dari berbagai profesi yang berbeda dalam tugas maupun responsibilitasnya, namun harus saling membantu dalam memberikan pelayanan kesehatan yang menyeluruh di rumah sakit. Belakangan ini sering muncul keluhan dari berbagai kalangan masyarakat tentang pelayanan rumah sakit yang kurang baik, bahkan tidak sedikit rumah sakit yang saat ini telah diminta pertanggungjawaban karena ketidaksesuaian pelayanan yang diberikan dengan apa yang diinginkan baik dari segi cita-cita ataupun tujuan serta peraturan yang ada. Suatu peraturan rumah sakit diperlukan untuk mengatasi segala permasalahan yang muncul didalam pengelolaan rumah sakit baik berupa perlindungan terhadap pasian yang membutuhkan pengobatan maupun terhadap kelalai yang dilakukan dokter dan rumah sakit dalam memberikan pelayanan. Peraturan harus saling berkesinambungan, pengawasan dan pembinaan harus jelas, serta potensi pekerjaan dan lembaga terkait harus diberdayakan secara optimal kinerjanya. Peraturan tersebut adalah hospital bylaws. Dasar hukum pelaksanaan hospital bylaws diatur dalam Peraturan Menteri Kesehatan RI Nomor 772 Tahun 2002 tentang Pedoman Peraturan Internal Rumah Sakit (Hospital Bylaws).

Akhir-akhir ini rumah sakit banyak mengalami masalah terhadap pelayanan yang diberikan. Mulai dari para dokter sampai para sopir ambulance pun mengalami penurunan dalan memberikan pelayanan kepada pasien dan juga keluarga pasien. Hal ini terbukti dan dapat kita lihat dengan melihat berita di media elektronik dan surat kabar.

Lampung merupakan salah satu provinsi yang juga memiliki pelayanan rumah sakit yang buruk dan dianggap kurang perhatian. Hal ini dapat kita lihat dengan cara mengetika kata kunci"rumah sakit Lampung"maka akan muncul hasil pencarian mengenai kurangnya pelayanan di rumah sakit. Oleh sebab itu penulis memilih salah satu kabupaten di Lampung yaitu Lampung Timur intuk melakukan penelitian mengenai hospital bylaws.

Secara luas, Hospital bylaws adalah seluruh ketetapan yang dibuat dan diberlakukan untuk suatu rumah sakit yang dapat berupa statuta atau anggaran dasar anggaran rumah tangga, peraturan standar dan lain sebagainya. Sedangkan secara sempit, Hospital bylaws adalah ketetapan yang berisikan aturan dalam hubungan antara komite medis, manajemen rumah sakit dan juga pemilik rumah sakit. ${ }^{1}$ Permasalahan dalam penelitian ini adalah bagaimana eksistensi hospital bylaws di rumah sakit? Apa saja aspek hukum keperdataan yang harus ada didalam sebuah hospital bylaws? Dan apakah keberadaan hospital bylaws ini sudah memberikan perlindungan hukum terhadap pemilik, pemimpin utama rumah sakit dan pegawai medis? Penelitian ini dilakukan melalui pendekatan yuridis normatif dan pendekatan yuridis empiris. Dalam penelitian ini data yang digunakan adalah data primer dan data sekunder, data-data ini dikumpulkan melalui studi pustaka dan studi lapangan, analisis data dilakukan secara kualitatif.

\section{B. Pembahasan}

\section{Eksistensi Hospital Bylaws di Rumah Sakit}

Sebuah rumah sakit memiliki tiga unsur yaitu pemilik atau yang mewakilkan, yang mengelola yaitu

\footnotetext{
${ }^{1}$ Joni Afriko, Hukum Kesehatan (Teori dan Aplikasinya), Bogor: In Media, (2016), hlm.56-57.
} 
pemimpin utama rumah sakit dan yang memberikan pelayanan yaitu pegawai medis. Tiga unsur tersebut disebut juga dengan "triad" atau "tiga tungku sejerangan". Dampak yang ditimbulkan dari perubahan rumah sakit yang semula unit sosial menjadi unit sosio ekonomi adalah rumah sakit menjadi lebih kompleks dan dikhawatirkan akan menimbulkan masalah apabila ikatan antara pemimpin utama rumah sakit, pegawai medis dan pemilik tidak di tata dengan baik. Oleh karena itu rumah sakit harus mengatur hubungan tiga unsur tersebut. Hospital bylaws berisikan pengaturan mengenai hubungan antara pemilik atau yang mewakilkan, pemimpin utama rumah sakit, dan pegawai medis yang merupakan peraturan internal tertinggi di dalam rumah sakit.

Untuk mengatur ketiga unsur tersebut maka diperlukan 2 (dua) peraturan internal yang menjadi ruang lingkup hospital bylaws, yaitu pertama peraturan internal corporate (corporate bylaws) mengenai ikatan pemilik atau yang mewakilkan dengan pemimpin utama rumah sakit dan kedua peraturan internal pegawai medis (medical staff bylaws) yaitu tentang pegawai medis. Karena merupakan peraturan internal tertinggi maka hospital bylaws dijadikan rujukan dalam penyelesaian masalah di rumah sakit. Untuk melihat eksistensi hospital bylaws suatu rumah sakit, kita dapat berpedoman dengan pendapat Meuwissen yaitu, keabsahan norma hukum, dalam arti "keberlakuan" -nya, apabila terpenuhinya salah satu syarat yaitu aturan yang dibuat tidak bertentangan dengan peraturan lainnya yang lebih tinggi dan sudah sesuai dengan prosedur yang benar atau biasa disebut keberlakuan yuridis. Keabsahan suatu aturan hukum diperlukan karena validitasi aturan salah satu fungsinya adalah untuk mengetahui keberadaan dari suatu aturan hukum. ${ }^{2}$

Untuk memahami eksistensi hospital byaws di rumah sakit di Kabupaten Lampung Tengah, penulis melakukan wawancara dengan Dinas Kesehatan Kabupaten Lampung Tengah selaku wakil dari pemilik rumah sakit pemerintah sekaligus pembina rumah sakit yang ada di Kabupaten Lampung Tengah, Pemilik rumah sakit swasta serta pemimpin utama rumah sakit pemerintah dan swasta. Menurut drg.Dian Yamasanti, semua rumah sakit di Kabupaten Lampung Tengah sudah memiliki hospital bylaws. Hanya saja belum semua rumah sakit menerapkan hospital bylaws dalam menyelesaikan masalah ataupun menjadikan hospital bylaws sebagai pedoman pelaksanaan pemberian pelayanan kesehatan di rumah sakit ${ }^{3}$

Menurut beberapa responden dari rumah sakit milik pemerintah ataupun milik swasta antara lain adalah: Menurut dr. Aidi, hospital bylaws yang ada belum digunakan sebagai tumpuan dalam melaksanakan penyelenggaraan rumah sakit dan belum menjadi rujukan penyelesaian masalah. Hospital bylaws hanya sebatas untuk memenuhi persyaratan perizinan dan akreditasi saja. ${ }^{4}$ Menurut pendapat Soeprapto, dr. Titin Prihartini, Samsu Rizal dan dr. Ari Hidayat, hospital bylaws yang ada di rumah sakit untuk bagian peraturan internal corporate (corporate bylaws) dibuat oleh pemilik dan digunakan apabila corporate mengalami masalah. Untuk bagian medical staff bylaws atau peraturan internal pegawai medis dibuat oleh pemimpin utama rumah sakit dan dibantu komite medik. Hanya saja hospital bylaws belum sepenuhnya dipergunakan untuk mengatasi masalah yang ada. Hal ini diakibatkan karena hospital bylaws yang ada di rumah sakit belum memuat semua aturan yang dibutuhkan rumah sakit. Misalnya apabila terjadi permasalahan dengan dokter tamu dan profesi perawat. Peraturan belum dibuat lebih rinci tentang hal itu. ${ }^{5}$ Menurut Afdi Muslim dan dr. Imilia Safitri mengatakan bahwa untuk pembuatan hospital bylaws pada bagian peraturan internal corporate (corporate bylaws) dilakukan oleh pemilik atau yang mewakili (badan hukum berbentuk PT). Untuk permasalahan terkait corporate, aturan tersebut dijadikan pedoman pemilik dalam penyelesaian masalah. Untuk medical staff bylaws atau peraturan internal pegawai medis sendiri dibuat oleh pemimpin utama rumah sakit dan dibantu oleh komite medik. Penerapan hospital bylaws sudah mengikuti Peraturan Menteri Kesehatan RI Nomor 772 Tahun 2002 tentang Pedoman Peraturan Internal Rumah Sakit (hospital bylaws). Peraturan internal pegawai medis (medical staff bylaws) dapat digunakan oleh pimpinan rumah sakit untuk mengatasi apabila terjadi permasalahan dengan pegawai medis. ${ }^{6}$

\footnotetext{
${ }^{2}$ Munir Fuady, Teori-Teori Besar (Grand Theory) Dalam Hukum, Jakarta: Kencana, (2013), hlm.124.

${ }^{3}$ Menurut drg. Dian Yamasanti, M.H.Kes., selaku Kepala Bidang Pelayanan Kesehatan Dinas Kesehatan Lampung Tengah, Kamis, 2 Februari 2017.

${ }^{4}$ Menurut dr.Aidi, M.KKK., selaku Kepala Bidang Pelayanan Medis RSUD Demang Sepulau Raya Gunung Sugih, Jumat, 3 Februari 2017.

${ }^{5}$ Hasil wawancara dengan H. Soeprapto, selaku wakil dari pemilik RS Yukum Medical Centre Bandar Jaya; dr. Titin Prihartini, selaku Pemimpin utama RS Yukum Medical Centre Bandar Jaya, Senin 27 Februari 2017 ; Samsu Rizal, S.E., MARS, selaku wakil dari pemilik RS Harapan Bunda Seputih Jaya; dr. Ari Hidayat, selaku Pemimpin utama RS Harapan Bunda Seputih Jaya, Selasa, 28 Februari 2017.

${ }^{6}$ Hasil wawancara dengan H. Afdi Muslim, S.E., selaku pemilik RS Islam Asy Syifaa Bandar Jaya; dr. Imilia Safitri, selaku Pemimpin utama RS Islam Asy Syifaa Bandar Jaya, Rabu, 1 Maret 2017.
} 
Menurut Agustina, dr. I Luh Sri Wahyuni, Elva Zuita, dr.Ali Irsal, dr. I Made Gede Bagiadha, dr.Adhyanovic Pradipta, Priskila Ngatmini, dr. Ukhron Novansyah, Meria Holistina dan dr. Hernowo Anggoro Wasono mengatakan bahwa mereka tidak memahami apa yang dimaksud dengan hospital bylaws dan beranggapan bahwa ini hanya digunakan untuk persyaratan perizinan dan akreditasi saja. Hal ini dikarenakan dalam pembuatan hospital bylaws pemilik dibantu oleh pihak ketiga sehingga belum memuat semua aturan yang dibutuhkan oleh rumah sakit. Hospital bylaws yang ada belum dijadikan pedoman dalam penyelesaian konflik, baik konflik di dalam corporate maupun pegawai medis. ${ }^{7}$

Berdasarkan hasil wawancara beberapa responden dapat dipahami bahwa rumah sakit di Kabupaten Lampung Tengah semuanya sudah mempunyai hospital bylaws. Dari sembilan rumah sakit yang ada di Kabupaten Lampung Tengah, hanya satu yang sudah menerapkan hospital bylaws sepenuhnya yaitu RS Islam Asy Syifaa Bandar Jaya. Sedangkan delapan rumah sakit lainnya belum sepenuhnya menjalankan hospital bylaws sesuai dengan Peraturan Menteri Kesehatan RI Nomor 772 tahun 2002 tentang Peraturan Internal Rumah Sakit (Hospital Bylaws). Dari hasil penelitian tersebut, penulis melihat ada bebrapa faktor yang menyebabkan hospital bylaws menjadi kurang eksistensinya di rumah sakit, yaitu:

1. Masih rendahnya tingkat pengetahun dan pemahaman dari pemilik, pemimpin utama rumah sakit serta pegawai medis tentang hospital bylaws Ini dapat dilihat dari tidak dipergunakannya hospital bylaws yang sudah dibuat oleh rumah sakit dalam menyelesaikan konflik atau pengambilan kebijakan. Mereka masih menganggap bahwa hospital bylaws yang dibuat hanya dipergunakan sebagai syarat perizinan dan akreditasi saja.

2. Kurangnya kesadaran dari pemilik tentang fungsi dari hospital bylaws yang sudah dibuat oleh rumah sakit. Seperti kita ketahui beberapa fungsi dari hospital bylaws adalah:

a) Sebagai tumpuan untuk pemilik dalam mengawasi rumah sakitnya. Apabila pemilik tidak mengetahui tentang hospital bylaws, maka pemilik tidak dapat mengetahui hal apa saja yang perlu diawasi dan bisa menimbulkan konflik. Sehingga pemilik akan kesulitan dalam mencari pemecahan masalahnya.

b) Sebagai tumpuan untuk pemimpin utama rumah sakit dalam pengelolaan rumah sakit dan membuat kebijakan. Seorang pemimpin utama yang sudah diberi kewenangan oleh pemilik untuk mengelola penyelenggaraan pelayanan di rumah dan tidak memahami apa isi dari hospital bylaws maka akan kesulitan untk membuat kebijakan teknis operasional dan apabila terjadi konflik dengan pemilik dan pegawai medis akan sulit mencari pemecahannya.

3. Dalam membuat hospital bylaws, pihak rumah sakit terkadang hanya melihat dari rumah sakit lain dan isinya belum memuat aturan yang rinci dan tegas serta tidak disesuaikan dengan situasi kondisi serta kebutuhan rumah sakit.

Seperti diketahui bahwa peraturan internal rumah sakit (hospital bylaws) adalah "tailor made", yang artinya peraturan internal setiap rumah sakit semestinya berbeda dengan lainnya karena beberapa faktor penyebabnya seperti halnya: sejarah awal berdirinya, status kepemilikan, situasi dan kondisinya yang berlainan di setiap rumah sakit. Ciri dan substansi yang ada di dalam hospital bylaws disebutkan bahwa aturan yang termuat harus tegas, jelas dan detail. Contoh misalnya, pada peraturan internal pegawai medis (medical staff bylaws) sudah disebutkan adanya dokter tamu, akan tetapi kewenangan dan tanggung jawab hukumnya apabila terjadi suatu kasus pada saat dokter tersebut memberikan tindakan medis tidak disebutkan.

Penerapan hospital bylaws di rumah sakit yang tidak maksimal akan berakibat kepada pasien. Rumah sakit sebagai lembaga yang cukup pelik dan memiliki risiko tinggi (high risk), baik dalam lingkungan regional maupun global yang perubahannya dapat dirasakan. Clinical governance merupakan salah satu dasar dari pelayanan medis, dengan pegawai medis yang menjadi faktor mendominasi. Dibentuknya komite medik sebagai penyusun peraturan internal staf medik (medical staff bylaws) bertujuan agar terjaminya mutu pelayanan medis dan melindungi keselamatan pasien dengan memberikan tata kelolaklinis (clinical governance) yang baik. Berdasarkan ketentuan peraturan perundang-undangan mengenai pengaturan perumahsakitan, rumah sakit bertanggung jawab atas seluruh pelayanan medis dan dampak yang ditimbulkannya. Semua pelayanan medis yang diberikan oleh pegawai medis harus diatur dengan baik oleh rumah sakit agar terjaminnya keamanan pasien.

\footnotetext{
${ }^{7}$ Hasil wawancara dengan Elva Zuita, selaku pemilik RSIA Puti Bungsu Bandar Jaya; dr. Ali Irsal, Sp.OG, selaku Pemimpin utama RSIA Puti Bungsu,Kamis, 2 Maret 2017; Dra. Agustina, selaku pemilik RS Mitra Mulia Husada; dr. I Luh Sri Wahyuni, selaku Pemimpin utama RS Mitra Mulia Husada Bandar Jaya, Senin, 6 Maret 2017; dr. I Made Gede Bagiadha, Sp.OG, selaku Pemilik RSIA Puri Adhya Paramita Bandar Jaya; dr. Adhyanovic Pradipta, selaku Pemimpin utama RSIA Puri Adhya Paramita Bandar Jaya.
} 


\section{Aspek Hukum Keperdataan yang Harus Ada di Dalam Hospital Bylaws}

Hukum merupakan seluruh aturan yang mengatur perilaku setiap individu dalam hubungan bermasyarakat atau bernegara serta dapat dikenakan sanksi jika melanggar. Hukum perdata adalah seluruh ketentuan hukum yang mengatur hubungan antar individu dalam masyarakat ${ }^{8}$ Subjek hukum adalah setiap orang yang mempunyai hak dan kewajiban serta kedudukan yang sama. Terdapat dua subjek hukum yaitu orang (manusia) dan badan hukum. Hubungan hukum (rechtsbetrekkingen) adalah hubungan mengenai hak dan kewajiban antar subjek hukum. ${ }^{9}$ Hak atau bevoegdheid dan kewajiban atau plicht adalah dua segi pasif dalam setiap hubungan hukum. Suatu peristiwa hukum akan menimbulkan hak dan kewajiban. ${ }^{10}$ Dari penjelasan di atas dapat dipahami bahwa apabila adanya dasar hukum yaitu peraturan yang mengatur serta timbul peristiwa hukum maka akan menimbulkan yang namanya hubungan hukum. ${ }^{11}$

Di hukum perdata, dalam mengadakan suatu hubungan dengan rumah sakit, baik itu pasien, manager, pegawai medis atau non medis dan lain sebagainya yang secara sadar dilakukan oleh para pihak, hospital bylaws dapat digunakan sebagai perjanjian baku untuk mengatur hubungan tersebut. Hospital bylaws mengatur hubungan hukum antara pemilik atau yang mewakilkan dengan pemimpin utama rumah sakit dan pegawai medis serta mengatur hubungan hukum antara pemimpin utama dan pegawai medis. Adanya perikatan atau perjanjian menguatkan suatu hubungan hukum. Hubungan hukum yang terjadi antar individu akan menimbulkan hak dan kewajiban bagi para pihak yang harus dilakukan dengan itikad baik dan tidak dibatalkan secara sepihak karena hal ini bersifat mengikat. ${ }^{12}$ Peristiwa hukum tersebut menimbulkan hubungan hukum antar pihak. Hak dan kewajiban dari pemilik, pemimpin utama rumah sakit dan pegawai medis diatur oleh Hospital bylaws.

Peraturan internal corporate menjelaskan governing body adalah pemilik atau yang mewakilkan memiliki peranan dalam menentukan tujuan rumah sakit, mengawasi kualitas dan keterjangkauan pelayanan, meningkatkan kedudukan masyarakat dan melakukan menyatukan dan mengatur suatu rumah sakit. Kewenangan dari pemimpin utama rumah sakit adalah menentukan kebijakan teknis operasional dengan berpedoman pada peraturan internal rumah sakit (hospital bylaws). Kebijakan yang dimaksud yaitu kebijakan di bidang administrasi, medis dan penunjang medis serta keperawatan. Kebijakan lainnya yaitu secara teknis yang dapat berbentuk surat keputusan. Dalam membuat surat keputusan harus berdasarkan pelimpahan wewenang yang terdapat dalam peraturan internal rumah sakit (hospital bylaws). Hubungan hukum antara pemimpin utama rumah sakit dan pegawai medis dapat dilihat dari kewenangan pemimpin utama medis untuk membentuk komite medik dan komite keperawatan. Pemimpin utama rumah sakit juga berkewajiban membuatkan penugasan klinis kepada pegawai medis serta mempunyai kewajiban dalam menjalanakan profesionalisme pegawai medis agar komite medik berjalan dengan baik untuk mempersiapkan semua sumber daya sesuai dengan ketentuan Peraturan Menteri Kesehatan RI Nomor 755 Tahun 2011 tentang Komite Medik di Rumah Sakit. Laporan tahunan dan berkala tentang kegiatan yang dilakukan wajib dilaporkan oleh ketua komite medik / komite keperawatan kepada pemimpin utama rumah sakit. Komite medik juga mempunyai kewajiban sebagai pengarah (steering).

Menurut drg. Dian Yamasanti, hospital bylaws di rumah sakit belum memuat semua aturan yang diharuskan oleh Peraturan Menteri Kesehatan RI Nomor 772 Tahun 2002 tentang Pedoman Peraturan Internal Rumah Sakit (Hospital Bylaws) dan penerapan serta pemahaman kewenangan antara pemilik dan pemimpin utama serta staf medis masih belum jelas. Pemilik masih saja turut campur kewenangan pemimpin utama yang bertugas sebagai pengelola pelayanan kesehatan di rumah sakit. Pegawai medis juga sering lupa akan batas kewenangannya, sehingga pegawai medis sering mencampuri kewenangan pemimpin utama rumah sakit dalam pengelolaan pelayanan nya. ${ }^{13}$ Menurut beberapa responden yang berasal dari rumah sakit mengenai hal tersebut di atas adalah sebagai berikut:

Menurut dr. Aidi, pemilik, pengelola dan pegawai medis belum memahami tentang hospital bylaws sehingga tidak memahami juga bagaimana hubungan hukum antara pemilik dengan pemimpin utama,

\footnotetext{
${ }^{8}$ Abdulkadir Muhammad, Hukum Perdata Indonesia, Bandung: Citra Aditya Bakti, (2014), hlm. 2.

${ }^{9}$ Ibid., hlm. 16.

${ }^{10}$ R. Soeroso, Pengantar Ilmu Hukum, Jakarta: Sinar Grafika, (2014), hlm. 270.

${ }^{11}$ Ibid., hlm. 271.

12 Ibid., hlm. 3.

${ }^{13}$ Hasil wawancara dengan drg.Dian Yamasanti, M.H.Kes, selaku Kepala Bidang Pelayanan Kesehatan Dinas Kesehatan Kabupaten Lampung Tengah, Kamis, 2 Februari 2017.
} 
hubungan hukum antara pemimpin utama rumah sakit dengan pegawai medis. Masing-masing pihak baik pemilik, pengelola dan pegawai medis tidak mengetahui batas kewenangan / kewajibannya. Sehingga sering terjadi konflik antara pemimpin utama rumah sakit dan pegawai medis. ${ }^{14}$ Menurut Soeprapto dan Samsu Rizal selaku pemilik masih menganggap bahwa pemilik masih memiliki kewenangan untuk turut campur dalam hal operasional rumah sakit yang seharusnya sudah menjadi hak dan kewajiban seorang pemimpin utama rumah sakit. Pemilik sebagai pemilik modal merasa punya kewajiban untuk terlibat dalam pengelolaan di rumah sakit. ${ }^{15}$

Menurut dr.Titin Prihartini dan dr. Ary Hidayat, aturan yang dibuat dalam hospital bylaws sudah tampak disebutkan hak serta kewajiban antara pemilik, pengelola dan pegawai medis. Akan tetapi pada kenyataannya banyak yang tidak sesuai. Pemilik masih mencampuri kewenangan pemimpin utama rumah sakit dalam hal kebijakan operasional dan cenderung bertindak secara otoriter. Pemilik terkadang tidak berkonsultasi dengan pemimpin utama apabila akan ada kebijakan penambahan unit baru, renovasi gedung dan penambahan alat. Komite medik yang sudah terbentuk di rumah sakit belum berjalan secara rutin, banyak program kerja yang tersendat pengerjaannya. Akan tetapi pemimpin utama rumah sakit selalu melibatkan komite medik dalam memutuskan kebijakan terkait pegawai medis. Sebagai contoh ketika terjadi konflik dengan pegawai medis, maka pemimpin utama rumah sakit mengkonsultasikan dan mendapatkan saran untuk menentukan kebijakan untuk mengatasi masalah dengan pegawai medis tersebut. Komite keperawatan sudah terbentuk, akan tetapi belum berjalan sesuai dengan Peraturan Menteri Kesehatan RI Nomor 49 Tahun 2013 tentang Komite Keperawatan Di Rumah Sakit. Belum memiliki peraturan internal staf keperawatan (nursing staf bylaws). ${ }^{16}$

Menurut Afdi Muslim dan dr.Imilia Safitri mengatakan bahwa pemimpin utama rumah sakit sudah diberi kewenangan penuh oleh pemilik dalam melakukan pengelolaan rumah sakit. Hal-hal yang memerlukan pendapat dari pemilik sudah dikoordinasikan dengan baik oleh pemimpin utama rumah sakit. Hubungan antara pemilik dengan pemimpin utama rumah sakit juga terbina dengan baik sehingga apabila pemilik melakukan tindakan di luar kewenangannya, maka pemimpin utama rumah sakit akan mengingatkan. Contohnya apabila pemilik menegur langsung staf keperawatan di rumah sakit, yang semestinya itu adalah kewenangan pemimpin utama rumah sakit. Maka pemimpin utama rumah sakit akan mengingatkan pemilik bahwa itu bukan wewenang pemilik. ${ }^{17}$ Menurut Elva Zuita, dr. Ali Irsal, Agustina, dr. I Luh Sriwahyuni, dr. I Gede Made Bagiadha, dr. Adhyanovic Pradipta, Meria Holistina, dr. Ukhron Novansyah, Priskila Ngatmini dan dr. Hernowo Anggoro Wasono mengatakan bahwa pemilik dan pemimpin utama rumah sakit belum memahami hak dan kewajiban serta batas kewenangannya masing-masing.

Hal ini dikarenakan sebagai pemimpin utama rumah sakit belum terlibat penuh dalam pengelolaan rumah sakit. Sehingga semua yang bersifat kebijakan operasional masih ditanggung sepenuhnya oleh pemilik. Hubungan pegawai medis, belum berjalan sesuai aturan. Hanya sebatas pada hubungan kerja antara majikan dan staf. Peraturan internal rumah sakit hanya dijadikan syarat dalam perizinan dan akreditasi saja. Komite medik belum berjalan sesuai aturan yang ada dan komite keperawatan belum dibentuk. ${ }^{18}$ Dari hasil wawancara beberapa responden baik rumah sakit pemerintah maupun swasta dapat diketahui bahwa belum semua rumah sakit yang memiliki hospital bylaws memahami apa saja aspek hukum keperdataan yang terdapat di dalam hospital bylaws yang mereka buat. Ini dapat dilihat dari aturan-aturan yang dibuat belum memuat secara keseluruhan mengenai tanggu jawab dari setiap orang yang merupakan bagian dalam pelayanan serta hak dan kewajiban yang dimilikinya, misalnya aturan untuk dokter tamu dan perawat. Karena merupakan produk hukum internal rumah sakit maka hospital bylaws akan memberikan kepastian

\footnotetext{
${ }^{14}$ Hasil wawancara dengan dr. Aidi, M.KKK, selaku Kepala Bidang Pelayanan Medik RSUD Demang Sepulau Raya Gunung Sugih, Jumat, 3 Februari 2017.

${ }^{15}$ Hasil wawancara dengan H.Soeprapto, selaku wakil dari pemilik RS Yukum Medical Centre, Bandar Jaya, Senin, 27 Februari 2016; Samsu Rizal, S.E., MARS, selaku wakil pemilik RS Harapan Bunda Seputih Jaya, Selasa, 28 Februari 2017.

${ }^{16}$ Hasil wawancara dengan dr. Titin Prihartini, selaku Pemimpin utama RS Yukum Medical Centre Bandar Jaya, Senin, 27 Februari 2017; dr. Ari Hidayat, selaku Pemimpin utama RS Harapan Bunda Seputih Jaya, Selasa, 28 Februari 2017.

${ }^{17}$ Hasil wawancara dengan H. Afdi Muslim, S.E., selaku wakil dari pemilik RS Islam Asy Syifaa Bandar Jaya; dr. Imilia Safitri, selaku Pemimpin utama RS Islam Asy Syifaa Bandar Jaya, Rabu, 1 Maret 2017.

${ }^{18}$ Hasil wawancara dengan Elva Zuita, selaku pemilik RSIA Puti Bungsu Bandar Jaya; dr. Ali Irsal, Sp.OG, selaku Pemimpin utama RSIA Puti Bungsu Bandar Jaya, Kamis, 2 Maret 2017; Dra. Agustina, selaku pemilik RS Mitra Mulia Husada Bandar Jaya; dr. I Luh Sriwahyuni, selaku Pemimpin utama RS Mitra Mulia Husada Bandar jaya, Kamis, 6 Maret 2017; Meria Holistina, selaku pemilik RS Az Zahra Kalirejo; dr. Ukhron Novansyah, Sp.OG, selaku Pemimpin utama RS Az Zahra Kalirejo, Sabtu, 11 Maret 2017; Priskila Ngatmini, selaku pemilik RS Kartini Kalirejo; dr. Hernowo Anggoro Wasono, selaku Pemimpin utama RS Kartini Kalirejo, Sabtu, 11 Maret 2017.
} 
hukum untuk setiap orang yang menjadi bagian di dalamnya terutama pemilik, pemimpin utama rumah sakit dan pegawai medis.

Kepastian hukum memiliki hubungan yang sangat erat dengan hukum tertulis. Hospital bylaws memberikan kepastian hukum dikarenakan di dalam aturan tersebut sudah disebutkan hak dan kewajiban masing-masing pihak. Adanya hak dan kewajiban ini maka terlihat sebatas mana kewenangan dari pemilik, pemimpin utama rumah sakit dan pegawai medis. Dari kewenangan tersebut maka pemilik, pemimpin utama rumah sakit dan pegawai medis akan mempunyai tanggung jawab hukum. Uraian tersebut sudah jelas bahwa semua tanggung jawab rumah sakit sudah termuat di dalam hospital bylaws.

\section{Perlindungan Hukum Yang Diberikan Oleh Hospital Bylaws Bagi Pemilik, Pemimpin Utama Rumah Sakit dan Pegawai Medis}

Hospital bylaws memiliki fungsi yang salah satunya yaitu menjadi sarana perlindungan hukum untuk seluruh pihak dalam pelayanan kesehatan di rumah sakit. Menurut drg. Dian Yamasanti, apabila hospital bylaws sudah memuat semua aturan hak dan kewajiban serta kewenangan baik pemilik, pemimpin utama rumah sakit dan pegawai medis maka perlindungan hukum mampu diberikan oleh hospital bylaws. ${ }^{19}$

Hasil wawancara beberapa responden yang bersumber dari rumah sakit milik pemerintah ataupun rumah sakit swasta adalah sebagai berikut:

Menurut Soeprapto, Samsu Rizal dan Afdi Muslim, mengatakan bahwa untuk masalah perlindungan hukum karena pemilik diwakili oleh badan hukum berbentuk PT yang menaungi penyelenggaraan rumah sakit, maka dengan aturan yang sudah termuat di dalam peraturan internal corporate (corporate bylaws) sudah jelas kewenangan dan tanggung jawab hukumnya. Sehingga pemilik berpendapat perlindungan hukum mampu diberikan hospital bylaws kepada para pihak yang terlibat dalam penyelenggaraannya. ${ }^{20}$ Menurut dr. Titin Prihartini dan dr. Ary Hidayat mengatakan bahwa untuk aturan yang sudah termuat dalam hospital bylaws yang dimiliki oleh rumah sakit maka akan memberikan perlindungan hukum kepada para pihak yang terlibat dalam penyelenggaraan rumah sakit. Hanya saja untuk rumah sakit yang beliau pimpin belum mempunyai peraturan internal pegawai keperawatan (nursing staf bylaws). Sehingga perlindungan untuk perawat masih harus dipikirkan apabila terjadi konflik. ${ }^{21}$

Menurut dr. Imilia Safitri, dengan adanya aturan yang jelas maka perlindungan hukum mampu diberikan oleh hospital bylaws kepada pemilik, pemimpin utama rumah sakit dan pegawai medis. Karena dari hospital bylaws yang ada, pemimpin utama bisa membuat kebijakan teknis operasional untuk para pelaksana pelayanan agar perlindungan masyarakat akan terjamin dengan diberikannya kualitas pelayanan kesehatan yang baik oleh para pelaksana pelayanannya. ${ }^{22}$ Menurut dr. Aidi, Elva Zuita,dr. Ali Irsal, Agustina, dr. I Luh Sriwahyuni, dr. I Made Gede Bagiadha, dr. Adhyanovic Pradipta, Meria Holistina, dr. Ukhron Novansyah, Priskila Ngatmini dan dr. Hernowo Anggoro Wasono mengatakan bahwa rendahnya pemahaman mereka tentang hospital bylaws, pemilik dan pemimpin utama rumah sakit belum merasakan bahwa perlindungan hukum mampu diberikan hospital bylaws kepada pemilik, pemimpin utama rumah sakit dan pegawai medis. $^{23}$

Dari pendapat beberapa responden yang bersumber dari Dinas Kesehatan Kabupaten Lampung Tengah, pihak rumah sakit baik pemerintah maupun swasta dapat disimpulkan bahwa bagi rumah sakit yang memang sudah menerapkan hospital bylaws maka rumah sakit yakin bahwa perlindungan hukum mampu di berikan hospital bylaws kepada pemilik, pemimpin utama rumah sakit dan pegawai medis. Akan tetapi untuk rumah

\footnotetext{
${ }^{19}$ Hasil wawancara dengan drg. Dian Yamasanti, M.H.Kes, selaku Kepala Bidang Pelayanan Kesehatan Dinas Kesehatan Kabupaten Lampung Tengah, Kamis, 2 Februari 2017.

${ }^{20}$ Hasil wawancara dengan H. Soeprapto, selaku wakil dari pemilik RS Yukum Medical Centre, Bandar Jaya, Senin, 27 Februari 2017; Samsu Rizal, S.E., MARS, selaku pemilik RS Harapan Bunda Bandar Jaya, Selasa, 28 Februari 2017; H. Afdi Muslim, S.E, selaku Pemilik RS Islam Asy Syifaa Bandar jaya, Rabu, 1 Maret 2017.

${ }^{21}$ Hasil wawancara dengan dr. Titin Prihartini, selaku Pemimpin utama RS Yukum Medical Centre, Bandar Jaya, Senin, 6 Februari 2017; dr. Ary Hidayat, selaku Pemimpin utama RS Harapan Bunda Bandar Jaya, Selasa, 28 Februari 2017.

${ }^{22}$ Hasil wawancara dengan dr.Imilia Safitri, selaku Pemimpin utama RS Islam Asy Syifaa, Bandar Jaya, Rabu, 1 Maret 2018

${ }^{23}$ Hasil wawancara dengan dr. Aidi, M.KKK, selaku Kabid Pelayanan Medik RSUD Demang Sepulau Raya Gunung Sugih, Jumat, 3 Februari 2017; Elva Zuita, selaku wakil dari pemilik RSIA Puti Bungsu, Bandar Jaya; dr. Ali Irsal, Sp.OG, selaku Pemimpin utama RSIA Puti Bungsu Bandar Jaya, Kamis, 2 Maret 2017; dr. I Made Gede Bagiadha, Sp.OG, selaku Pemilik RSIA Puri Adhya Paramita Bandar Jaya; dr. Adhyanovic Pradipta, selaku Pemimpin utama RSIA Puri Adhya Paramita, Selasa, 7 Maret 2017; Meria Holistina, selaku pemilik RS Az Zahra Kalirejo; dr. Ukhron Novansyah, Sp.OG, selaku pemimpin utama RS Az Zahra Kalirejo, Sabtu, 11 Maret 2017; Priskila Ngatmini, selaku pemilik RS Kartini Kalirejo; dr. Hernowo Anggoro Wasono, selaku Pemimpin utama RS Kartini Kalirejo, Sabtu, 11 Maret 2017.
} 
sakit yang belum menerapkan hospital bylaws dan beranggapan bahwa hospital bylaws hanya digunakan untuk kelengkapan perizinan dan akreditasi, maka akan dikatakan perlindungan hukum belum mampu diberikan hospital bylaws kepada pemilik, pemimpin utama rumah sakit dan pegawai medis.

\section{Kesimpulan}

Berdasarkan penjelasan tersebut, maka kesimpulan yang dapat diambil yaitu sebagai berikut:

1. Hospital bylaws sebagai aturan-aturan yang disusun rumah sakit yang berisi mengenai pengaturan tentang hubungan antara pegawai medis, pemimpin utama dan pemilik pada kenyataannya eksistensinya belum sesuai dengan apa yang diharapkan.

2. Hospital bylaws yang ada di rumah sakit belum memuat aspek hukum keperdataan secara lebih rinci dan tegas.

3. Rendahnya tingkat pengetahuan dan pemahaman pemilik, pemimpin utama rumah sakit dan pegawai medis sehingga dalam pembuatan hospital bylaws belum memuat aturan secara rinci dan tegas, hal ini mengakibatkan beberapa rumah sakit menganggap bahwa perlindungan hukum belum bisa diberikan hospital bylaws kepada pemilik, pemimpin utama rumah sakit dan pegawai medis.

\section{DAFTAR PUSTAKA}

\section{A. Buku}

Afriko, Joni. (2016). Hukum Kesehatan (Teori dan Aplikasinya). Bogor: In Media

Fuady, Munir. (2013). Teori-teori Besar (Grand Theory) Dalam Hukum. Jakarta: Kencana.

Muhamad, Abdulkadir. (2004). Hukum dan Penelitian Hukum.Cetakan pertama. Bandung: Citra Aditya Bakti

Muhamad, Abdulkadir. (2014). Hukum Perdata Indonesia. Bandung: Citra Aditya Bakti.

Soeroso. (2013). Pengantar Ilmu Hukum. Bandung: Bumi Aksara

\section{B. Peraturan}

Keputusan Menteri Kesehatan RI Nomor 772 Tahun 2009 Tentang Peraturan Internal Rumah Sakit (Hospital Bylaws)

Peraturan Menteri Kesehatan RI Nomor 49 Tahun 2013 Tentang Komite Keperawatan Rumah Sakit

Peraturan Menteri Kesehatan RI Nomor 755 Tahun 2011 Tentang Penyelenggaraan Komite Medik Di Rumah Sakit.

Undang-Undang Nomor 44 Tahun 2009 tentang Rumah Sakit 